\title{
Evaluating Long-Term Survival of Patients with Esophageal Cancer using Parametric Non-Mixture Cure Rate Models
}

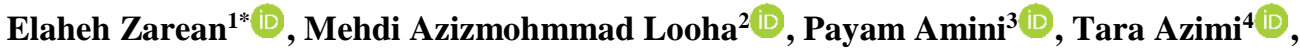 \\ Mahmoud Mahmoudi ${ }^{5}$ iD
}

\begin{abstract}
1. Modeling in Health Research Center, Shahrekord University of Medical Sciences, Shahrekord, Iran
2. Dept. of Biostatistics, School of Paramedical Sciences, Shahid Beheshti University of Medical Science, Tehran, Iran.

3. Reproductive Epidemiology Research Center, Royan Institute for Reproductive Biomedicine, ACECR, Tehran, Iran.

4. School of Public Health, University of Alberta, Edmonton, Alberta, Canada.

5.Dept. of Epidemiology and Biostatistics, School of Public Health, Tehran University of Medical Sciences, Tehran, Iran
\end{abstract}

\begin{abstract}
Article Info
$10.30699 /$ jambs.27.120.43

Received: $2018 / 11 / 21$

Accepted: 2019/02/24;

Published Online: 02 Feb 2019;

Use your device to scan and read the article online

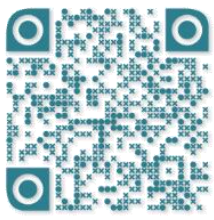

Corresponding Information: Elaheh Zarean, Modeling in Health Research Center, Shahrekord University of Medical Sciences, Shahrekord, Iran Email: elahe.zarean.ez@gmail.com

ABSTRACT

Background \& Objective: Esophageal cancer (EC) has been identified as one of the most common cancers in the northeastern regions of Iran. In our study, parametric non-mixture cure rate model was applied to evaluate the effects of risk factors on the long-term survival of patients with EC in East Azerbaijan, Northeastern Iran

Materials \& Methods: This retrospective cohort study of 127 patients with EC registered at Iran National Cancer Registry office in the period 2009-2010. These patients were followed up for 5 years in East Azerbaijan, Iran until 2015. The best parametric cure rate model was identified and the risk factors of survival in patients with $\mathrm{EC}$ were measured by Akaike Information Criteria and parametric non-mixture cure rate model, respectively.

Results: The survival time of EC patients ranged 0.10-69.03 months. Male sex (Odds Ratio $(\mathrm{OR})=0.08,95 \%$ confidence interval $(\mathrm{CI}$ : $0.02-0.32, P<0.001)$, patients who underwent esophagectomy surgery $(\mathrm{OR}=6.11,95 \% \mathrm{CI}$ : $1.46-25.55, P=0.013)$ had a significant effect on the survival and the cure fraction of EC patients. Population cure rate was 0.11 (95\%CI: 0.07-0.19) and cure fraction was estimated $4.9 \%$.

Conclusion: The Weibull non-mixture cure rate model was the most appropriate statistical tool to identify potential risk factors that affect both survival and cure fraction of EC patients. It is a recommended tool for analyzing the long-term survival of patients with EC.
\end{abstract}

Keywords: Esophageal neoplasms, Survival analysis, Non-mixture Cure Rate models

\section{Introduction}

In recent decades, cancer has become a serious public health problem worldwide. Cancer rates are decreasing in western countries such as the United States, while in less developed and developing countries, including Eastern European countries, which have an unhealthy western lifestyle, cancer rates are increasing $(1,2)$. According to the National Cancer Registry (NCR) reports, after coronary disease, accidents, and natural phenomena, cancer is considered as the third main cause of death, in Iran (3). Esophageal cancer (EC) is a deadly malignancy which has caused the premature death in patients in advanced stages $(4,5)$. Based on the recent meta-analysis conducted on the incidence of esophageal cancer, the incidence rate of this cancer was reported eighty-four percent in developing countries (6). Also in 2013, 442000 new cases of esophageal cancer were diagnosed and 440000 patients with esophageal cancer experienced death due to this cancer worldwide (7). It is anticipated that the prevalence rates of esophageal cancer will increase by $140 \%$ by $2025(8)$. EC is the $8^{\text {th }}$ most common cancer with regard to incidence and the $6^{\text {th }}$ highest with regard to mortality (9). Medical researchers have achieved advanced progress in Diagnosis and treatment of esophageal cancer, but the survival rate of patients with esophageal cancer ranges from $15 \%$ to $20 \%$. Patients who are diagnosed in the early stages have had the high survival rate associated with disease (5). Geographic and racial differences have had an important role in the incidence of esophageal cancer across the world (4). Surgery is known as a definitive treatment for esophageal cancer. However, surgical techniques can also impact the increase of survival in patients with EC (4). Radiotherapy and chemotherapy are other major treatment options in patients with esophageal cancer. Previous medical research shows that using chemotherapy and radiotherapy improved the treatment and survival of patients with locally advanced esophageal cancer $(10,11)$. Upper gastrointestinal tract cancers were 
observed as the most common cause of death in the Caspian littoral of Iran. Furthermore, esophageal, stomach and colon cancer had had a high incidence in this region and the Eastern Azerbaijan province (12-14). Recent studies revealed that the incidence rate of esophageal cancer is higher in women than in men and that patients with esophageal cancer aged 50-70 years old have had highest incidence rates $(12,15)$. Multiple epidemiological studies revealed that smoking consumption, alcohol drinking, socioeconomic status, gender and the age at diagnosis are important risk factors that affect the survival of patients with esophageal cancer (15-20). According to reports from the Iranian Ministry of Health, gastrointestinal tract cancers such as esophageal and gastric cancers are the most common cancers in the East Azerbaijan province (21). Unfortunately, few studies have been conducted on the occurrence of gastrointestinal tract cancers, their survival rates and the risk factors associated with this diseases (22).

Clinical researchers have achieved progress in the treatment of chronic diseases in last few decades. These achievements have increased the proportion of cured patients from many types of cancers (23). In this case, the population group could be split into two sub groups including long-term survivors (those who are being cured) and short-term survivors (those who are non-cured). In such situations, using common survival approaches like proportional hazard model could not provide accurate estimations due to a large number of censoring items at the end of the follow-up period which, accurately, could not estimate the survival probability of those with longterm survival (24). Nevertheless, a non-mixture cure model or bounded cumulative hazard model uses a different approach for modeling survival and cure fraction parts of the model (25).

In the Current study, we compare the parametric forms of non-mixture cure rate model in a retrospective cohort study to analyze the effects of risk factors on survival and cure fraction of patients with esophageal cancer.

\section{Materials and Methods}

This registry-based retrospective cohort study was conducted in East-Azerbaijan on 399 patients with gastrointestinal cancers during the years 2009-2010 who registered at Iran National Cancer Registry office in Iran's Cancer Registration Program and were followed up till 2015. In this national program, all pathology centers, health centers, and hospitals in provinces are obligated to report their data to the Cancer Office of Disease Control and Prevention (26). Sampling was done in a full-census manner and the dataset of this study was collected from 127 cases of patients with EC who lived in cities including Azarshahr, Osku, Ahar, Bostanabad, Bonab, Tabriz, Jolfa, Chroymagh, Sarab, and Shabestar in the East-Azerbaijan Province.

The type of cancer site in this study was defined according to the International Classification of Diseases, 10th revision. $127 \mathrm{EC}$ patients was defined by code $\mathrm{C} 15$. In order to assess the potential risk factors of EC, patients with prior cancers were excluded from this study. Also, there is no loss to follow-up in this study. Figure 1 showed Flow chart of patients who met inclusion/exclusion criteria for the study population. In addition, the current study data is extracted from an MSc thesis which was checked and approved by the Ethics Committee of the TUMS (IR.TUMS.DDRI.REC.1396.4148).

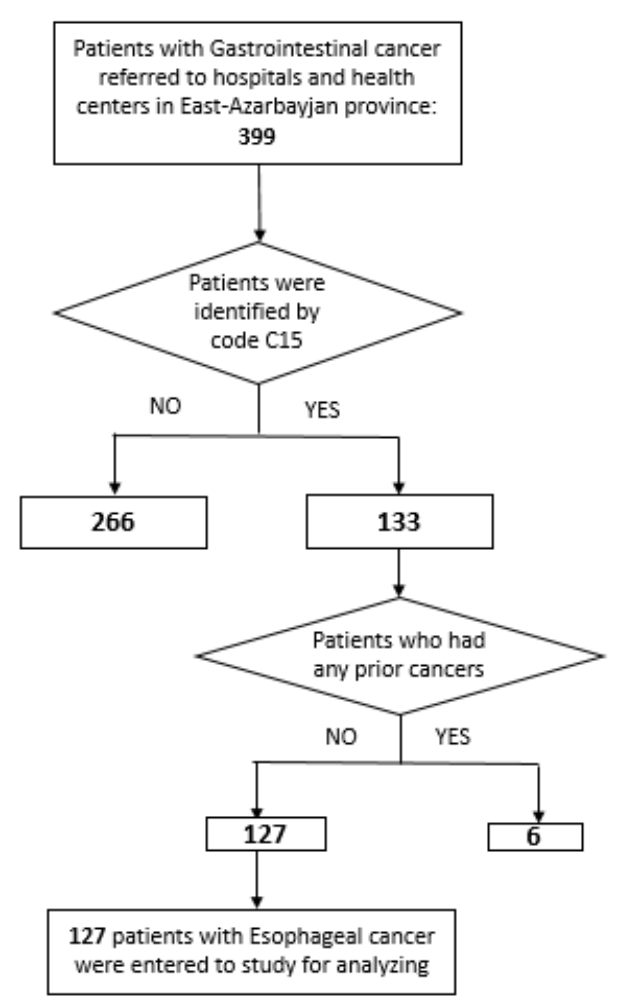

Figure 1. Flow chart of patients who met inclusion/exclusion criteria for the study population

The patients that were referred to health centers and hospitals in this province were followed up for five years until 2015. The patients' information were extracted from their records in hospitals and health centers. The patients were contacted via phone to collect data on their health and survival information. The beginning of the study was assumed as the pathologic diagnosis of the cancer. The study outcome was considered death due to EC. Survival time was calculated by the difference between the dates of death and the first report of their cancer pathology. Patients who survived by the end of the study were considered as right censored. Dying as a result of esophageal cancer was considered as failure in this study. Furthermore, the survival time in long-term survival group was measured as the time interval between the date of EC diagnosis and the date of EC patients' last followup time. Meanwhile, for short-term survivors the interval time between the date of EC diagnosis and the date of their death due to EC was regarded as their survival time.

The data collection included demographic information (e.g., the age at the time of diagnosis, gender, educational status, marital status, and employment status) and the biological and clinical variables (e.g., non-communicable 
disease (NCD) affected status, smoking habits, Esophagectomy surgery, chemotherapy, and radiotherapy). In addition, socioeconomic status (SES) obtained based on a checklist of wealth and social position characteristics such as household fuel consumption, residential facilities, personal family facilities, and household appliances used by the family, total monthly household income, education status, and job status.

Principle component factor analysis was applied to obtain the socioeconomic status $(\mathrm{KMO}=0.722$, Bartlett's Sphericity test $P<0.001)$. The extracted score categorized by the median to low and high level.

\section{Statistical Analysis}

Demographic, biological and clinical characteristics of patients were entered in the log-rank test to assess the unadjusted effect of variables. Descriptive characteristics of the patients were expressed as the mean \pm standard deviation (SD) and frequency (percentage) for continuous categorical variables.

The Kaplan-Meier survival plot was used to reveal if the plot reached zero with the current amount of follow up time. The plot contributed to finding the proportion of survived cases. In the case of a high survival rate, Cox regression model leads to bias estimates. In this situation, Cure rate models can be proper tools to investigate what risk factors are associated with survival of cured and uncured patients. Cure rate models are categorized into two major forms; mixture cure rate model and nonmixture cure rate model (27). In 1999, the second method was presented as a non-mixture cure rate model by Chen et al. (28). A non-mixture cure rate model is known as a bounded cumulative hazard model. This model uses different approaches to model the survival and cure fraction parts of the model. Covariates interpretation is not the same for these two kinds of cure rate models $(29,30)$.

In this model, a log-log link function was used and the survival function can be written as follows:

$$
S(t)=p^{F_{0}(t)}=\exp \left(\ln (p) F_{0}(t)\right]
$$

Where $F_{0}(t)=1-S_{0}(t)$ is expressed as the cumulative distribution function for the non-cured group (29).

In order to determine the best subset which has the best fit on a Cox proportional hazards model, stepwise selection could be a suitable approach. Therefore, this method was applied in this study to obtain a subset with variables having $0.2<P<0.1$ to achieve the most accurate estimations. Another method which was taken to account to check the indicators of multicollinearity among variables was Variance Inflation Factor (VIF). This method provides an opportunity to measure the value of variance of the estimated regression coefficient' inflation through calculating the amount of correlation between model's predictor variables. It should be noted that the chosen subset fitted to parametric non-mixture cure models was the one which was already used to fit the Cox proportional hazards model in this study.

In current study, estimating the quality of parametric non- mixture cure rate models was determined by Akaike Information Criteria (Log-logistic, Log-Normal, Weibull and Exponential are used as parametric distributions in non-mixture cure rate model).

Odds ratio (OR) estimations of Weibull non-mixture cure rate model were displayed as our results. It should be taken into consideration that OR estimations in a nonmixture cure rate model defined by a logit link could demonstrate that in which variable group the odds of being cured is higher than the other one. Therefore, in this model if the value of odds is higher than one, it could be, indeed, true that the odds of being cured is greater than the baseline group and vice versa (29).

Moreover, the $95 \%$ confidence intervals for the estimated effect sizes were demonstrated as 95\% Confidence Interval (CI). The data were analyzed using R software version 3.4.2, and the figures was prepared by STATA version 12 . The $\mathrm{P}$ value $<0.05$ was considered statistically significant.

\section{Results}

Our study was performed on 127 esophageal cancer patients, aged 35-88 years old. A total of 113 (89\%) cases experienced the death due to esophageal cancer and 14 (11\%) were alive by the end of the study. The survival time ranges of patients with EC were from 0.10 to 69.03 months. One, three and five-year survival probabilities were 0.44 (95\% confidence interval (CI): 0.36-0.54), 0.2 (95\% CI: $0.14-0.28)$ and 0.13 (95\% CI: $0.08-0.2)$ respectively. The mean ( \pm standard deviation) age at diagnosis was $66.92( \pm 11.95)$ years old. The mean and median survival time in non-cure group were 16.99 (95\% CI: 13.46-20.52) and 10.06 (95\% CI: 6.49-13.63) months respectively. The patients' characteristics and Log-rank test results are shown in Table 1.

Sex, Esophagectomy surgery, marital status, SES, and radiotherapy are determined as the best subset variables by stepwise selection. This subset fit on the Cox proportional hazards model while the presence of multicollinearity between covariates was considered based on the VIF values. The PH assumption is checked in the Cox regression model and the assumption was rejected $(P=0.035)$. Therefore, the Cox proportional hazards model was not appropriate for the dataset. According to the AICs from parametric non-mixture cure rate models, the Weibull non-mixture cure model outperformed other approaches (Weibull: $\mathrm{AIC}=826.61$, Exponential: $\mathrm{AIC}=832.96$, Log-logistic: $\mathrm{AIC}=829.16$, Lognormal: $\mathrm{AIC}=832.16$ ).

\section{Table 1. The Esophageal Cancer patients' characteristics and the results of log-rank Test}




\begin{tabular}{|c|c|c|c|c|c|}
\hline & & & Log & Test & \\
\hline Variable & $\mathbf{N}(\%)$ & Death $113(89 \%)$ & Mean Survival Time & $\mathrm{SE}^{*}$ & P-value \\
\hline Age' & & & & & 0.460 \\
\hline$\geq 50$ & $113(89)$ & $101(89.4)$ & 10.28 & 0.93 & \\
\hline$<50$ & $14(11)$ & $12(85.7)$ & 12.76 & 2.60 & \\
\hline Gend & & & & & 0.103 \\
\hline Male & $70(55.1)$ & $68(97.1)$ & 9.21 & 1.03 & \\
\hline Female & $57(44.9)$ & $45(78.9)$ & 12.56 & 1.54 & \\
\hline Educa & & & & & 0.836 \\
\hline Illiterate $* * *$ & $98(77.2)$ & $87(88.8)$ & 10.58 & 1.05 & \\
\hline Literate & $29(22.8)$ & $26(89.7)$ & 10.40 & 1.46 & \\
\hline Marital & & & & & 0.011 \\
\hline Married & $86(67.7)$ & $35(85.4)$ & 11.88 & 1.11 & \\
\hline Unmarried $* * *$ & $41(32.3)$ & $78(90.7)$ & 7.57 & 1.24 & \\
\hline Job St & & & & & 0.062 \\
\hline Unemployed $* * * *$ & $79(62.2)$ & $67(84.8)$ & 11.93 & 1.21 & \\
\hline Employed & $48(37.8)$ & $46(95.8)$ & 8.51 & 1.16 & \\
\hline Smoking & & & & & 0.181 \\
\hline Yes & $42(33.1)$ & $40(95.2)$ & 12.08 & 1.62 & \\
\hline No & $85(66.9)$ & $73(85.9)$ & 9.70 & 1.01 & \\
\hline NCD affect & tatus & & & & 0.721 \\
\hline No & 103 (81.1) & $93(90.3)$ & 10.63 & 0.98 & \\
\hline Yes & 24 (18.9) & $20(83.3)$ & 10.11 & 1.96 & \\
\hline Esophagecton & urgery & & & & 0.048 \\
\hline Yes & $72(56.7)$ & $59(81.9)$ & 12.22 & 1.34 & \\
\hline No & $55(43.3)$ & $54(98.2)$ & 8.71 & 1.04 & \\
\hline Chemoth & & & & & 0.009 \\
\hline Yes & $55(43.3)$ & $51(92.7)$ & 13.18 & 1.41 & \\
\hline No & $72(56.7)$ & $62(86.1)$ & 8.38 & 1.02 & \\
\hline Radioth & & & & & 0.052 \\
\hline Yes & 43(33.9) & $39(90.7)$ & 13.32 & 1.44 & \\
\hline No & $84(66.1)$ & $74(88.1)$ & 9.08 & 1.06 & \\
\hline SES**: & & & & & 0.022 \\
\hline High level & $66(52)$ & $62(93.9)$ & 12.52 & 1.52 & \\
\hline Low level & $61(48)$ & $51(83.6)$ & 12.55 & 0.94 & \\
\hline $\begin{array}{l}\text { *Standard Error } \\
\text { **Age at diagnosis } \\
\text { *** Illiterate: patients } \\
\text { **** Unmarried: patien } \\
\text { *****Unemployed: pat } \\
\text { ******SES: socioecon }\end{array}$ & $\begin{array}{l}\text { no academic } \\
\text { were single, } \\
\text { ho were retir } \\
\text { tatus }\end{array}$ & $\begin{array}{l}\text { tion were considered as } \\
\text { ed or widow were enter } \\
\text { ad no job were conside }\end{array}$ & $\begin{array}{l}\text { te. } \\
\text { nmarried group. } \\
\text { inemployed. }\end{array}$ & & \\
\hline
\end{tabular}

The results of weibull non-mixture cure rate model with logit link function are demonstrated in Table 2. According to the estimations, odds ratio of males group is reported 0.08 so males had lower odds to be cured of esophageal cancer in comparison to females $(\mathrm{OR}=0.08,95 \% \mathrm{CI}$ : $0.02-0.32, P<0.001)$. Odds of being cured from death in those who underwent Esophagectomy surgery was 6.11 times higher than the other group $(\mathrm{OR}=6.11$; 95\%CI: $1.46-25.55, P=0.013)$.
As shown in Figure 2, the Kaplan-Meier curve is stabled at the probability of almost 0.11 , which implies that the population cure rate is 11 percent (Standard Deviation $=0.01,95 \%$ CI: $0.07-0.19)$. In addition, the obtained cure fraction was estimated to be $4.9 \%$, which was reasonable compared to population cure rate.

The Kaplan-Meier survival curves of best subset variables is shown in Figure 3. Kaplan-Meier curves for gender, SES, Esophagectomy surgery, marital status and radiotherapy demonstrated that survival odds of cure 
among the females group, patients who were in the high level socioeconomic condition, patients with EC who underwent Esophagectomy surgery, married group and patients who received radiotherapy greater than among the male group, patients who were in the low level socioeconomic condition, no Esophagectomy surgery and unmarried group and people who didn't receive radiotherapy respectively.

Table 2. Estimation Based on Weibull Non-mixture Cure rate Model with logit link function

\begin{tabular}{|c|c|c|c|c|c|}
\hline \multirow{2}{*}{ Variable } & \multirow{2}{*}{ OR* } & \multirow{2}{*}{$\mathrm{SE}^{* * *}$} & \multicolumn{2}{|c|}{$95 \% \mathrm{CI}^{* * * *}$} & \multirow{2}{*}{ P-value } \\
\hline & & & lower & upper & \\
\hline Sex (Male) & 0.08 & 0.70 & 0.02 & 0.32 & $<0.001$ \\
\hline SES **** ( Low level) & 2.70 & 0.58 & 0.86 & 8.47 & 0.089 \\
\hline Esophagectomy Surgery (Yes) & 6.11 & 0.73 & 1.46 & 25.55 & 0.013 \\
\hline Radiotherapy (Yes) & 2.14 & 0.56 & 0.71 & 6.46 & 0.177 \\
\hline Marital status ( Unmarried) & 0.30 & 0.65 & 0.08 & 1.05 & 0.060 \\
\hline
\end{tabular}

*Odds Ratio**Standard Error;***95\% confidence interval****socioeconomic status

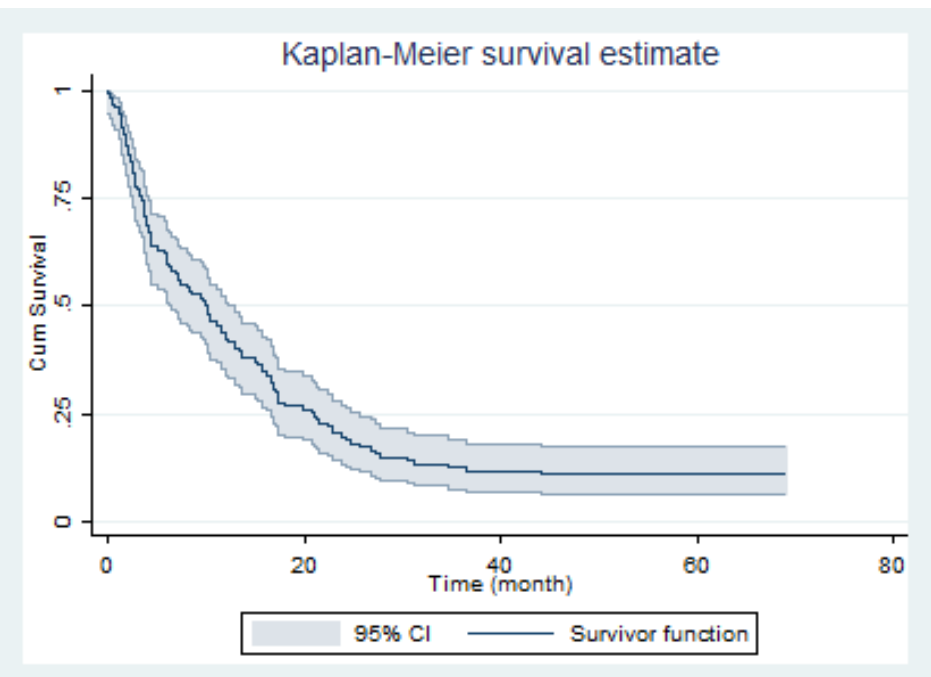

Figure 2. The Kaplan-Meier curve of patients with esophageal cancer
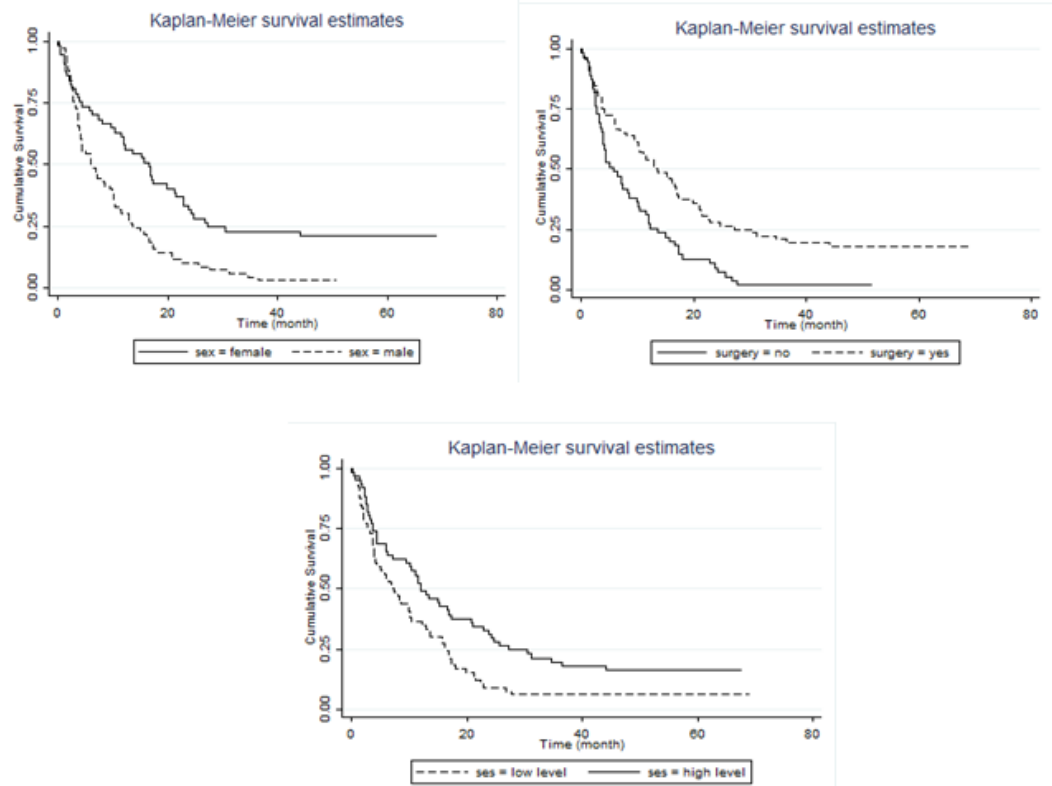

Figure 3. Kaplan-Meier survival curves of best subset variables 


\section{Discussion}

This study revealed that the survival time after the diagnosis of esophageal cancer is significantly affected by sex, marital status, job status, socioeconomic condition and Esophagectomy surgery. In our sample a high proportion of the patients died by the end of the study. In addition, the mean survival time was less than one year.

The current research demonstrated that a low socioeconomic condition can result in lower probability of survival of esophageal cancer. This might be due to the accessibility to utilities including chemotherapy, hormone therapy, surgery and other treatments. In a study by Louwman et al., the prevalence of life-shortening factors among cancer patients including esophageal with low socioeconomic status was investigated. They showed that cancer patients with a bad SES were more probable to suffer from alternative severe diseases. The negative outcomes after esophageal cancer diagnosis and its link with other diseases are more considerable among those with lower scores of SES (31). Tran et al. evaluated the effects of gender, race, socioeconomic status, and treatment on the survival of esophageal cancer patients. They revealed that poor SES is related to less chance of receiving surgery which can lower survival rates (32). In a similar research studies in Iran and India, the relationship between the risk of esophageal squamous cell carcinoma and socioeconomic status was examined and a strong relationship was observed $(33,34)$.

In our data, males were more likely to die prior to women. This finding can be the result of a more risky lifestyle for men such as smoking and tobacco usage, being an alcoholic, and engaging in poor lifestyle choices. In some studies, it is well discussed that EC is more common among men than women in Asian countries specially in Iran, but in a cross-sectional study Shokri Shrirvani et al. found that there is no significant difference in gender of patients with esophageal carcinoma $(35,36)$. Also the impact of gender difference on the survival of patients with esophageal cancer was explored by Bohanes et al. it was demonstrated that women have longer survival in both metastatic and locoregional esophageal cancer. The hormonal differences and menopause were the potential reasons for the controversy of the survival rates among the two genders (37). Mathieu et al studied the disparity in esophageal cancer between males and females. Regarding their results, it was established that estrogen is the main preventative factor against the cancer and this protective performance vanishes along with the females approach to Menopause (38).

We showed that Esophagectomy surgery increases the survival time of esophageal cancer. Surgery has been presented as the best treatment choice for esophageal cancer in early-stage. Moreover, treatments such as chemotherapy and radiation therapy are suggested for the later-stages of cancer in recent studies in Iran (39). In consistence with our result, D'Amico evaluated the consequences after surgery among patients with esophageal cancer. It was shown that chemotherapy after surgery can result in longer survival (40).

In recent years, due to increasing therapies for several types of cancer, the proportion of patients who do not experience the event of interest (cured) are significantly improved (41). The relative survival of patients will reach a plateau for these kinds of disease denoting that the mortality of patients who are cured is the same as expected in the common population (41). Yu et al. have proposed that, if there is a proportion of patients who are cured from the event under study, the estimations of classical survival model are biased and failed to converge (42). Since some cancer-related subjects may have long-term survival, cure rate models can be the appropriate method to characterize and study the patients' survival. Mixture and non-mixture are two general forms of cure models and the use of each model depends on the data (43). In order to avoid these potential problems, parametric non-mixture cure model was used in our study.

There were some limitations on the relatively small sample size in our data. Missing data was frequently observed in the patients' records gathered from hospitals and health centers and information about some other potential risk factors were not measured. However, there are lots of other factors related to the lifetime of esophageal cancer such as metastatic status, tumor size, the stage of disease and the certain type of esophageal cancer (adenocarcinoma and squamous). These prognostic factors were not assessed because of the lack of access to the medical records of patients in the EastAzerbaijan cancer registry.

\section{Conclusion}

In conclusion, although esophageal cancer is recognized as a malignant disease with a low survival rate, considerable improvement of therapies including surgery and radiotherapy for this cancer have been identified in the recent years. Current study have important clinical and public health implications in Northeastern Iran for monitoring the risk factor and survival time of patient with esophageal cancer. Furthermore, potential risk factors which affect the survival of patients who are not susceptible to the occurrence of the event under study can be determined by clinicians and researchers using appropriate survival analysis. In this study, gender and 
Esophagectomy surgery were determined as risk factors that affect both survival and cure fraction of EC patients. Therefore, due to more accurate and more reliable insight into long-term advantages of EC therapy, Weibull Nonmixture cure rate is recommended for analysis of longterm survival of patients with EC. Finally, as a clinical report, this study established 3 risk factor which should be taken into account in the screening, prevention and reduction of esophageal cancer.

\section{Acknowledgements}

The authors thank the Iran National Cancer Registry Office and Tehran University of Medical Sciences, Tehran, Iran for assistance with data gathering and collaboration.

\section{Conflict of Interest}

Authors declared no conflict of interests.

\section{References}

1. Jemal A, Center MM, DeSantis C, Ward EM. Global patterns of cancer incidence and mortality rates and trends. Cancer Epidemiol Prevent Biomarker. 2010; 19(8): 1893-907. [DOI:10.1158/1055-9965.EPI-10-0437] [PMID]

2. Siegel R, Ma J, Zou Z, Jemal A. Cancer statistics, 2014. CA: Cancer J Clinic. 2014; 64(1): 9-29. [DOI:10.3322/caac.21208] [PMID]

3. Mousavi SM, Gouya MM, Ramazani R, Davanlou M, Hajsadeghi N, Seddighi Z. Cancer incidence and mortality in Iran. Ann Oncol. 2009; 20(3): 556-63. [DOI:10.1093/annonc/mdn642] [PMID]

4. Napier KJ, Scheerer M, Misra S. Esophageal cancer: A Review of epidemiology, pathogenesis, staging workup and treatment modalities. World J Gastrointest Oncol. 2014; 6(5): 112-20. [DOI:10.4251/wigo.v6.i5.112] [PMID] [PMCID]

5. Pennathur A, Gibson MK, Jobe BA, Luketich JD. Oesophageal carcinoma. The Lancet. 2013; 381(9864): 400-12. [DOI:10.1016/S0140-6736(12)60643-6]

6. Salehiniya H, Hassanipour S, Mansour-Ghanaei F, et al. The incidence of esophageal cancer in Iran: A systematic review and meta-analysis. Biomed Res Ther. 2018; 5(7): 2493-503. [DOI:10.15419/bmrat.v5i7.459]

7. Siegel RL, Miller KD, Jemal A. Cancer statistics, 2017. CA: Cancer J Clinic. 2017; 67(1): 7-30. [DOI:10.3322/caac.21387] [PMID]

8. Lambert R, Hainaut P. The multidisciplinary management of gastrointestinal cancer. Epidemiology of oesophagogastric cancer. Best Prac Res Clin Gastroenterol. 2007; 21(6): 921-45. [DOI:10.1016/j.bpg.2007.10.001] [PMID]

9. Pennathur A, Gibson MK, Jobe BA, Luketich JD. Oesophageal carcinoma. Lancet. 2013; 381(9864): 400-12. [DOI:10.1016/S0140-6736(12)60643-6]

10. Liu J, Yue J, Xing L, Yu J. Present status and progress of neoadjuvant chemoradiotherapy for esophageal cancer. Front Med. 2013; 7(2): 172-9. [DOI:10.1007/s11684-013-0268-0] [PMID]
11. Ardalan B, Spector SA, Livingstone AS, et al. Neoadjuvant, surgery and adjuvant chemotherapy without radiation for esophageal cancer. Japan J Clin Oncol. 2007; 37(8): 590-6. [DOI:10.1093/jico/hym076] [PMID]

12. Kmet J, Mahboubi E. Esophageal cancer in the caspian littoral of Iran: Initial Studies. Science. 1972; 175(4024): 846-53. doi:10.1126/science.175.4024.846 [DOI:10.1126/science.175.4024.846] [PMID]

13. Islami F, Kamangar F, Aghcheli K, et al. Epidemiologic features of upper gastrointestinal tract cancers in Northeastern Iran. Br J Cancer. 2004; 90(7): 1402-6. [DOI:10.1038/sj.bjc.6601737] [PMID] [PMCID]

14. Somi MH, Farhang S, Mirinezhad SK, Naghashi S, Seif-Farshad M, Golzari M. Cancer in East Azerbaijan, Iran: results of a population-based cancer registry. Asian Pac J Cancer Prev. 2008; 9(2): 327-30.

15. Ghadimi MR, Mahmoodi M, Mohammad K, Rasouli M, Zeraati H, Fotouhi A. Factors affecting survival of patients with oesophageal cancer: a study using inverse Gaussian frailty models. Singapore Med J. 2012; 53(3): 336-43.

16. Gammon MD, Ahsan H, Schoenberg JB, et al. Tobacco, alcohol, and socioeconomic status and adenocarcinomas of the esophagus and gastric cardia. J National Cancer Inst. 1997; 89(17): 1277-84. [DOI:10.1093/jnci/89.17.1277] [PMID]

17. Gao YT, McLaughlin JK, Blot WJ, Ji BT, Dai Q, Fraumeni JF. Reduced risk of esophageal cancer associated with green tea consumption. J National Cancer Inst. 1994; 86(11): 855-8. [DOI:10.1093/jnci/86.11.855] [PMID]

18. Tuyns AJ, Riboli E, Doornbos G, Péquignot G. Diet and esophageal cancer in Calvados. Nutr Cancer. 1987; 9: 81-92. [DOI:10.1080/01635588709513915] [PMID]

19. Cook M, Chow W, Devesa S. Oesophageal cancer incidence in the United States by race, sex, and histologic type, 1977-2005. Br J Cancer. 2009; 101(5): 855-9. [DOI:10.1038/sj.bjc.6605246] [PMID] [PMCID]

20. Tavani A, Bertuzzi M, Talamini R, et al. Coffee and tea intake and risk of oral, pharyngeal and esophageal cancer. Oral Oncol. 2003; 39(7): 695-700. [DOI:10.1016/S1368-8375(03)00081-2]

21. Khosravi A, Taylor R, Naghavi M, Lopez AD. Mortality in the Islamic Republic of Iran, 1964-2004. Bull World Health Org. 2007; 85: 607-14. [DOI:10.2471/BLT.06.038802] [PMID] [PMCID]

22. Zarean E, Yaseri M, Mahmoodi M, Entezar Mahdi R. Factors affecting long-term survival rate with cure fraction using the mixture cure cox model in patients with gastric cancer in eastazerbaijan province, Iran. J School Pub Health Ins Pub Health Res. 2018; 15(4): 337-50.

23. Bremhorst V, Lambert P. Flexible estimation in cure survival models using Bayesian P-splines. Computational Statistics \& Data Analysis. 2016; 93: 270-84. [DOI:10.1016/j.csda.2014.05.009]

24. Harrell Jr FE. Regression modeling strategies: with applications to linear models, logistic and ordinal regression, and survival analysis: Springer; 2015.

25. Othus M, Mitchell A, Barlogie B, Morgan G, Crowley J. Curerate survival models and their application to cancer clinical trials. Front Biostatistic Method Application Clin Oncol: Springer. 2017; 165-78. [DOI:10.1007/978-981-10-0126-0 11] 
26. Center for Disease Control and Prevention, Ministry of Health and Medical Education (Iran). 2009-2010.

27. Andersson TM, Dickman PW, Eloranta S, Lambert PC. Estimating and modelling cure in population-based cancer studies within the framework of flexible parametric survival models. BMC Med Res Methodol. 2011; 11(1): 96. [DOI:10.1186/1471-2288-11-96] [PMID] [PMCID]

28. Chen MH, Ibrahim JG, Sinha D. A new Bayesian model for survival data with a surviving fraction. J Am Statistic Assoc. 1999; 94(447): [DOI:10.1080/01621459.1999.10474196]

29. Lambert PC, Thompson JR, Weston CL, Dickman PW. Estimating and modeling the cure fraction in population-based cancer survival analysis. Biostatistics. 2007; 8(3): 576-94. [DOI:10.1093/biostatistics/kx1030] [PMID]

30. Maetani S, Gamel JW. Parametric cure model versus proportional hazards model in survival analysis of breast cancer and other malignancies. Adv Breast Cancer Res. 2013; 2(04): 119. [DOI:10.4236/abcr.2013.24020]

31. Louwman W, Aarts M, Houterman S, Van Lenthe F, Coebergh J, Janssen-Heijnen M. A $50 \%$ higher prevalence of lifeshortening chronic conditions among cancer patients with low socioeconomic status. Br J Cancer. 2010; 103(11): 1742-48. [DOI:10.1038/sj.bjc.6605949] [PMID] [PMCID]

32. Tran PN, Taylor TH, Klempner SJ, Zell JA. The impact of gender, race, socioeconomic status, and treatment on outcomes in esophageal cancer: A population-based analysis. J Carcinog. 2017; 16: 3. [DOI:10.4103/jcar.JCar_4_17] [PMID] [PMCID]

33. Dar NA, Shah IA, Bhat GA, et al. Socioeconomic status and esophageal squamous cell carcinoma risk in Kashmir, India. Cancer Sci. 2013; 104(9): 1231-6. [DOI:10.1111/cas.12210] [PMID]

34. Golozar A, Etemadi A, Kamangar F, et al. Food preparation methods, drinking water source and esophageal squamous cell carcinoma in the high risk area of golestan, Northeast Iran. Europ
J Cancer Prev. 2016; 25(2): 123-9. [DOI:10.1097/CEJ.0000000000000156] [PMID] [PMCID]

35. Pakzad R, Mohammadian-Hafshejani A, Khosravi B, et al. The incidence and mortality of esophageal cancer and their relationship to development in Asia. Ann Transl Med. 2016; 4(2): 29. [DOI:10.1016/j.prnil.2015.09.001] [PMID] [PMCID]

36. Shokri Shirvani J, Siadati S, Imandoost F. Demographic, endoscopic and pathologic features of esophageal carcinoma. J Mazandaran Univ Med Sci. 2017; 27(150): 176-80.

37. Bohanes P, Yang D, Chhibar RS, et al. Influence of sex on the survival of patients with esophageal cancer. J Clin Oncol. 2012; 30(18): 2265-72. [DOI:10.1200/JCO.2011.38.8751] [PMID] [PMCID]

38. Mathieu LN, Kanarek N, Hooker C, Rudin CM, Brock M. Esophageal cancer gender disparity. American Society of Clinical Oncology; 2012. [DOI:10.1200/jco.2012.30.30 suppl.47]

39. Pourhoseingholi MA, Vahedi M, Baghestani AR. Burden of gastrointestinal cancer in Asia; an overview. Gastroenterol Hepatol Bed Bench. 2015; 8(1): 19-27.

40. D'Amico TA. Outcomes after surgery for esophageal cancer. Gastrointestinal cancer research: GCR. 2007; 1(5): 188.

41. Boussari O, Romain G, Remontet L, et al. A new approach to estimate time-to-cure from cancer registries data. Cancer Epidemiol. 2018; 53: 72-80. [DOI:10.1016/j.canep.2018.01.013] [PMID]

42. Yu B, Tiwari RC, Cronin KA, Feuer EJ. Cure fraction estimation from the mixture cure models for grouped survival data. Stat Med. 2004; 23: 1733-47. [DOI:10.1002/sim.1774] [PMID]

43. Swain PK, Grover G, Goel K. Mixture and non-mixture cure fraction models based on generalized gompertz distribution under Bayesian Approach. Tatra Mountains Mathematical Publications. 2016; 66(1): 121-35. [DOI:10.1515/tmmp-20160025]

\section{How to Cite This Article:}

Zaeran E, Azizimohammad Looha M, Amini P, Azimi T, Mahmoudi M. Evaluating Long-term survival of patients with esophageal cancer using parametric non-mixture cure rate models. J Adv Med Biomed Res. 2019; 27 (120) $\cdot 42-5 n$

Download citation:

$\underline{\text { BibTeX }}|\underline{\text { RIS }}| \underline{\text { EndNote }}|\underline{\text { Medlars }}| \underline{\text { ProCite }}|\underline{\text { Reference Manager }}| \underline{\text { RefWorks }}$

Send citation to:

(3) Mendeley 2 Zotero (i) RefWorks RefWorks 